\title{
PRODUZIR UM BOM TEXTO: TAREFA POSSÍVEL NO ENSINO SUPERIOR
}

Jayme Ferreira Bueno*

\section{Intoduçã o}

Ao iniciar esta exposição, pretendo esclarecer o que neste trabalho se considera um "bom texto". Aqui, o texto de qualidade é concebido como aquele cuja leitura se torna fluente e de fácil compreensão, por organizar-se de forma coesa e coerente e apresentar-se com uma linguagem adequada ao tema que, nele, está sendo desenvolvido. Forma e conteúdo ou, caso se prefira, significante e significado devem fundir-se num todo harmonioso. Esse todo, à semelhança de um ser vivo, apresentará suas partes devidamente ordenadas e agindo, não de modo isolado, cada uma por si, mas, de forma integrada, em função da nova unidade constituída, Assim já preconizava, na Antigüidade Clássica, o autor da Poética, ao tratar da estrutura do mito. (ARISTÓTELES, 1966, p.76)

Como segundo ponto, apresento o objetivo deste escrito, já sugerido no título, que é apontar para a possibilidade de se produzir texto com qualidade nos cursos universitánios. Os estudantes, em especial dos cursos de licenciatura, devem, primeiramente, aprender a redigir, para, depois, quando formados, exercendo o magistério, estarem aptos a ensinar técnicas e metodologias de elaboração de textos. Na área humanística, em especial naquela voltada para a formação de docentes, a prática de elaboração de texto deveria ser a norma e nunca a exceção.

\section{A poblemática}

Como professor no Curso de Letras e no de Mestrado em Educação

* Doutor em Letras, é professor do Programa de Mestrado em Educação da PUCPR. 
da PUCPR, tenho tido a oportunidade de orientar e de acompanhar a produção de texto, desde os mais simples aos mais complexos. O que se pode observar é a extrema dificuldade de se redigir texto com as qualidades imprescindíveis da coesão, coerência, adequação da linguagem e, por extensão, da clareza e aceitável correção.

A dificuldade de redigir, no contexto universitário brasileiro, pode ser perfeitamente compreendida. Ela se deve principalmente à ausência de tradição, no ensino do país, de práticas docentes que levem à produção de textos. As escolas superiores, de um modo geral, não têm oferecido as condições necessárias de conhecimento e de incentivo para a produção de texto, 0 que deveria ser uma prática comum na vida universitária. Por isso, o aluno não consegue redigir textos com razoável qualidade, ou seja, um texto que contenha as características da legibilidade e do entendimento decorrentes de uma estrutura coesa e coerente e que apresente uma linguagem adequada ao tema tratado. Só no ensino atual, por iniciativa de alguns professores e de alguns cursos, em especial de pós-graduação, é que se procura romper essa situação e suprir tal deficiência.

Integrado à linha de pesquisa Teoria e Prática Pedagógica na Educação Superior do Curso de Mestrado em Educação da PUCPR, venho lecionando nesse Programa, a disciplina Linguagem e Educação. Em decorrência dessa atividade, tenho orientado dissertações sobre leitura e sobre produção de textos universitários. Geralmente, a textualidade e seus elementos, em especial a coesão e a coerência, constituem os temas predominantes nessas pesquisas. Os mestrandos, apoiados em autores como KOCH (1996), KOCH \& TRAVAGLA (1996), CHAROLES (1978) e outros, enfocam esses dois elementos textuais como imprescindíveis para a organização do texto.

Já se tornou consenso em cursos, oficinas e outras atividades de produção de texto e também em textos teóricos sobre o tema, que os elementos estruturais, mais especificamente a coesão e a coerência, constituem as bases em que se assenta um texto de qualidade. Acrescente-se a essa situação o fato de alunos e professores virem sendo, freqüentemente, avaliados pelos textos que produzem. CIPRO NETO (2000), em sua coluna jornalística Inculta \& Bela, comenta: "Nas provas de português dos bons vestibulares, é cada vez mais comum que se exija do candidato a percepção da lógica e da coerência (con)textuais." Quanto aos professores, pode-se observar que um dos critérios de avaliação docente é o da produção científica, ou seja, o da publicação de textos. Pode-se considerar aqui, também, que coesão e coerência, embora em outro contexto, são considerados por DEMO (1989) critérios de cientificidade para trabalhos de pesquisa em ciências sociais. 


\section{Uma metodologia}

Dentro de uma proposta fundamentada na pesquisa-ação, conforme a conceitua, por exemplo, THIOLLENT (1992), tem-se procurado trabalhar de acordo com uma metodologia que privilegie: $1^{\mathrm{O}}$ - a análise inicial de textos produzidos por alunos sem uma orientação e sem uma pesquisa dos elemen-

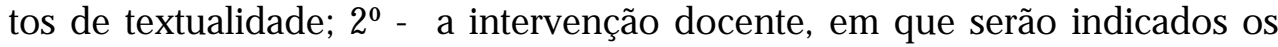
elementos textuais, para o estudo com pesquisa; $3^{0}$ - a reescrita dos textos sob a supervisão do professor. Essas três fases básicas da metodologia poderão subdividir-se em outras, dependendo da extensão e da complexidade do texto a ser produzido.

As três etapas metodológicas apresentadas buscam estabelecer uma prática pedagógica que leve o estudante universitário a redigir um texto que, teoricamente, apresente uma evolução qualitativa quanto à estruturação que inicialmente apresentava, ou seja, um texto mais coeso e mais coerente e, portanto, um bom texto. As pesquisas realizadas têm demonstrado que o aluno que redige com conhecimento teórico dos principais elementos textuais, e que recebe 0 acompanhamento, a orientação e o incentivo de um docente especializado na teoria e na prática da produção de texto, pode conseguir uma redação de melhor qualidade.

O texto universitário que se busca com ações docentes, como a referida, é um texto que se diferencie daquele texto desestruturado que o estudante geralmente apresenta antes de ingressar no ensino superior: um texto que, muitas vezes, apresenta-se de forma ilegível, por incompreensível, e ilógico, pela falta de coesão e de coerência. É aquele texto que costuma aparecer em situações como exercícios de escrita no ensino médio, em muitas das redações dos vestibulares e mesmo nos escritos dos primeiros anos dos cursos superiores. Esse texto, pela ausência da coesão e da coerência e pelo emprego de uma linguagem não adequada ao tema e à situação propostos, não se sustenta como estrutura lingüística capaz de transmitir informação ao leitor. Geralmente, constitui um discurso preestabelecido, que a escola repassou ao aluno como modelo, para ele tentar cumprir uma tarefa mecânica, a de "resolver o problema da redação". Nesse caso, pelo fato de o aluno não dominar as técnicas de redação e de não possuir as informações necessárias, pela falta de leitura e de estudo sobre o tema que irá enfocar, o texto soará falso e desligado da realidade.

\section{Leitura e pdução de tex to}

Como já se fez referência ao longo desta exposição, escrever é uma prática que depende de outra em especial, que é ler. A leitura e a escrita se complementam numa relação de interdependência. Uma necessita da outra, 
apóia-se na outra. Escrever é uma atividade que requer contínuo exercício e aprendizagem cotidiana, pela constante leitura e pela pesquisa dos temas a serem abordados. É de grande utilidade também a freqüente consulta a manuais de redação, gramáticas e dicionários. Embora com a discordância de alguns autores, a necessidade da leitura para a redação de texto parece ser óbvia. Só se pode redigir sobre aquilo que se conhece e, em termos de se adquirir conhecimentos, a leitura ainda é uma das fontes privilegiadas. De qualquer modo, o assunto ocupa as páginas dos periódicos especializados ou não: como exemplo, "Quem não lê não escreve" é o título de um artigo publicado na Folha de S. Paulo. (SOARES, 1997)

Na prática textual escolar, pelo menos a partir do ensino médio, 0 exercício de produção de texto deve vir antecedido da leitura de bons textos; neste caso, textos bem estruturados e com temática voltada aos interesses do aluno-leitor. $\mathrm{O}$ acompanhamento docente com o fornecimento de técnicas da gramática textual (lingüística textual) e de outras ciências ou disciplinas deve complementar o conhecimento obtido pela assimilação dos conteúdos do texto lido, tanto com referência ao assunto, quanto à estrutura formal. É comum afirmar-se que só se pode comunicar aquilo que, primeiro, conhecemos ou passamos a conhecer por fontes de informação, como a leitura de bons textos e o estudo com pesquisa. É por isso que as Universidades, há algum tempo, passaram a indicar aos vestibulandos livros para leitura. Atualmente, o MEC adotou também a lista de livros para o Exame Nacional de Cursos - Letras, mais conhecido por "provão".

\section{Conclusão}

Ao encerrar estes comentários, reitero três idéias: leitura e escrita devem constituir práticas privilegiadas nas escolas de ensino médio e nas universidades; os cursos e os docentes devem incorporar às suas atividades de ensino metodologias que contribuam para o aprender e para o ensinar e, também, para o aprender a ensinar a redigir; para aprender a redigir e para ensinar a redigir, deve-se buscar a leitura de bons textos, a pesquisa de outras fontes de informação e o contínuo exercício da escrita.

Finalizando, espero que, além do objetivo teórico de falar sobre a possibilidade de se construir um bom texto, tenha atingido um outro, no âmbito da prática, o de haver redigido um texto com as condições da legibilidade. 


\section{Referências Bibliográficas}

ARISTÓTELES. Poética. Trad. Brasileira de Eudoro de Sousa. Porto Alegre: Globo, 1966. (Col. Biblioteca dos Séculos)

BANDEIRA, Grace dos Anjos Freire. O ensino da língua portuguesa com o conhecimento do latim: uma análise dos fatores de textualidade em livros didáticos. Dissertação de mestrado. Curitiba: PUCPR, 1996.

CHAROLES, Michel. Introduction aux problèmes de la cohérence des textes. Paris: Langue Française, 1978.

CHIARELLO, Ilze Salete. A leitura e o ensino com pesquisa no curso superior: uma proposta de aprender a aprender. Dissertação de mestrado. Curitiba: PUCPR, 2000.

CIPRO NETO, Pasquale. O cinto, a causa e a conseqüência. In: Gazeta do Povo. Curitiba, 19 out. 2000.

DEMO, Pedro. Metodologia científica em ciências sociais. 2.ed. São Paulo:Atlas, 1989.

KOCH, Ingedore Villaça. A coesão textual. 7.ed. São Paulo: Contexto, 1997. (Col. Repensando a Língua Portuguesa)

KOCH, Ingedore Villaça \& TRAVAGLIA, Luiz Carlos. A coerência textual. 7.ed. São Paulo: Contexto, 1996. (Col. Repensando a Ĺngua Portuguesa)

KÜSTER, Ana Maria de Barros. O ensino com pesquisa e a produção do texto universitário: um estudo da coesão e da coerência textual. Dissertação de Mestrado. Curitiba: PUCPR, 1998.

SOARES, Wander. Quem não lê não escreve. In: Folha de S. Paulo. São Paulo: 24 fev.97.

THIOLENT, Michel. Metodologia da pesquisa-ação. São Paulo: Cortez, 1992. 